\title{
Importance of New Edible Oil Extracted from Seeds of Seven Cereals Species
}

\author{
Amor Slama (iD, ${ }^{1,2}$ Ammar Cherif $\mathbb{D D}^{1,3}$ and Sadok Boukhchina $\mathbb{D}^{1}$ \\ ${ }^{1}$ University of Tunis El Manar, Faculty of Sciences of Tunis, LR18ES03,Laboratory of Neurophysiology, \\ Cellular Physiopathology and Biomolecules Valorisation, Tunis 2092, Tunisia \\ ${ }^{2}$ University of Carthage, Faculty of Sciences of Bizerte, Jarzouna-Bizerte 7021, Tunisia \\ ${ }^{3}$ Department of Science Laboratories, College of Sciences and Arts, Qassim University, Ar Rass 51921, Saudi Arabia \\ Correspondence should be addressed to Amor Slama; slamaamor@yahoo.fr
}

Received 5 February 2021; Accepted 13 May 2021; Published 24 May 2021

Academic Editor: Antimo Di Maro

Copyright (c) 2021 Amor Slama et al. This is an open access article distributed under the Creative Commons Attribution License, which permits unrestricted use, distribution, and reproduction in any medium, provided the original work is properly cited.

\begin{abstract}
Cereals constitute a major source of human and animal nutrition. In spite of the extensive production of numerous cereal species, some information is unavailable in terms of lipid composition. Due to the oil increasing demand by the overgrowth of the world population, oleaginous species have encountered problems in recent years. In order to find new sources of edible oil, the aim of this study was to describe the importance of seventeen varieties oil of seven cereal species. Oils were extracted by the Soxhlet method, and fatty acids were measured by gas chromatography. The present study demonstrated that the lipid content of cereal seeds ranged from $1.42 \%$ to $5.97 \%$. In average, oat, millet, and maize had significantly higher lipid content, respectively, $5.97 \%$, $5.06 \%$, and $4.71 \%$. The main fatty acid recorded in the studied cereal species, except oat, was linoleic acid C18:2( $\omega 6)$. Regarding the essential fatty acids linoleic acid C18:2 and linolenic acid C18:3 ( $\omega 3)$, the oil of all studied species, except oat, was rich in $\omega 6$ fatty acids ( 47.50 to $60.13 \%)$ and poor in $\omega 3(0.45 \%$ to $5.33 \%)$. The content of unsaturated fatty acids in all studied species ranged from 77.22 to $81.89 \%$. Cereal oil was considered as highly unsaturated oil with the presence of the essential fatty acids necessary for human health. Therefore, cereal oils could be commercialized in small quantities in pharmacies or parapharmacies.
\end{abstract}

\section{Introduction}

Cereals, including durum and bread wheat, barley, triticale, maize, and millet, constitute a major source of human and animal nutrition in Tunisia. Differences may occur between those species in the composition of total lipids and fatty acids, which provide a variety of beneficial properties on different levels. Hence, the study of those components is essential for many raisons. Thus, cereal lipid is rich in essential fatty acids that cannot be synthesized by human body, necessary for cell membranes and nervous system [1]. The cereal seeds oil contains many monounsaturated and polyunsaturated fatty acids that participate in human physiology and different bioactive compounds that have significant clinical properties [2]. The polyunsaturated fatty acids are an essential component of the membrane phospholipids in some tissues and as a precursor of some hormones [3]. Nevertheless, the saturated fatty acids increase the risks of cancer, cardiovascular diseases, and autoimmune disorders [4]. The study of [5] showed that millet fatty acids play a significant hypoglycemic role. Whole grains of barley, wheat, oats, and rye are an important source of dietary fibers [6]. The authors in [7] found that cereal grains increased the amount of arachidonic, docosahexaenoic, polyunsaturated fatty acids, $\omega 3$ and $\omega 6$ acids in the liver tissue and decreased the total cholesterol level. Furthermore, fatty acids have caught also the attention of both consumers and industries [2]. Wheat lipids show an important role in bread making despite its minor proportion compared to starch and protein [8] and in the storage stability of cerealbased food or feed [9].

The composition and structure of lipids have a great importance on the bread making and influence the end-use quality of bread [10]. In the end of mixing of wheat flour, 
TABLE 1: Cereal species and varieties used in the present study.

\begin{tabular}{|c|c|}
\hline Species & Varieties \\
\hline $\begin{array}{l}\text { Durum wheat (Triticum durum } \\
\text { Desf.) }\end{array}$ & $\begin{array}{l}\text { Khiar-Karim-Razzak- } \\
\text { Maali }\end{array}$ \\
\hline Bread wheat (Triticum aestivum L.) & $\begin{array}{c}\text { Salambo-Byrsa-Utique- } \\
\text { Aicha }\end{array}$ \\
\hline Barley (Hordeum vulgare L.) & Manel-Kounouz-Rihane \\
\hline osecale Wittmack) & $\mathrm{Tcl} 3$ \\
\hline tiva L.) & Bysantina-Fretissa \\
\hline Maize (Zea mays L.) & Grombalia \\
\hline Pearl millet (Pennisetum glaucum L.) & Médenine (ecotype) \\
\hline
\end{tabular}

part of the lipid crystals and the developed gluten complex stabilize the interface [8]. Wheat lipids play also an essential role in other food systems such as pasta, cakes, and cookies and determine the quality of those foods; the cooking quality of couscous was partially dependent on the content and composition of semolina free lipids [11]. For sorghum, maize, rice, and millet flour, pasting properties were also influenced by free fatty acids mainly palmitic, oleic, and linoleic acids [12]. The authors in [13] showed that combination of fatty acids and amylose contributed to the pasting properties in barley and total lipids and individual fatty acids determine the malt quality. Consequently, it is important to analyze the lipid composition of cereal grains. The present study aims to examine the total lipid content and fatty acids of seventeen varieties of seven cereal species grown in Tunisia.

\section{Materials and Methods}

2.1. Plant Material. The varieties used in this study were derived from lines of seven cereal species, most cultivated in Tunisia (Table 1).

2.2. Lipid Extraction and Fatty Acid Determination. The lipid contents were determined by Soxhlet extraction on $100 \mathrm{~g}$ of whole each variety grains. Three replications of $25 \mathrm{~g}$ of milled fine powder were used for extraction of lipid by petroleum ether for four hours.

To determine the content of fatty acids, $100 \mu \mathrm{L}$ of extracted lipid from each replication (3) was converted to fatty acid methyl esters. We added to the extracted lipid $2 \mathrm{~mL}$ of heptane and $0.2 \mathrm{~mL}$ of $2 \mathrm{~N}$ methanolic potassium. Then, the mixture was shaken and after standing $1 \mu \mathrm{L}$ of the upper phase was injected in the column with a $0.25 \mathrm{~mm}$ diameter of the gas chromatography. Nitrogen was used as carrier gas with a flow rate of $25 \mathrm{ml} / \mathrm{min}$ in splitless mode. The total program duration was $18 \mathrm{~min}$ with a rising temperature from $180^{\circ} \mathrm{C}$ to $240^{\circ} \mathrm{C}$. The temperature of injector and detector temperatures was kept at $300^{\circ} \mathrm{C}$.

A standard of fatty acid methyl esters mixture was used to identify the fatty acids peaks.

2.3. Statistical Analyses. Statistical analyses were conducted using SAS program. Analysis of variance was used to compare the means of triplicate. Differences were considered significant at $P<0.05$ using Duncan's multiple range.
TABLE 2: Variation of total lipid (\%) of the cereal varieties.

\begin{tabular}{|c|c|c|c|c|c|}
\hline Species & & Culti & ars & & $\operatorname{Pr}$ \\
\hline $\begin{array}{l}\text { Durum } \\
\text { wheat }\end{array}$ & $\begin{array}{l}\text { Maali } \\
1.88^{\mathrm{A}}\end{array}$ & $\begin{array}{c}\text { Razzak } \\
1.84^{\mathrm{A}}\end{array}$ & $\begin{array}{c}\text { Karim } \\
1.82^{\mathrm{A}}\end{array}$ & $\begin{array}{l}\text { Khiar } \\
1.70^{\mathrm{A}}\end{array}$ & 0.512 \\
\hline $\begin{array}{l}\text { Bread } \\
\text { wheat }\end{array}$ & $\begin{array}{l}\text { Aicha } \\
1.85^{\mathrm{A}}\end{array}$ & $\begin{array}{l}\text { Utique } \\
1.74^{\mathrm{B}}\end{array}$ & $\begin{array}{l}\text { Byrsa } \\
1.64^{\mathrm{C}}\end{array}$ & $\begin{array}{c}\text { Salambo } \\
1.52^{\mathrm{D}}\end{array}$ & $0.000^{* *}$ \\
\hline Barley & $\begin{array}{c}\text { Rihane } \\
1.99^{\mathrm{A}}\end{array}$ & $\begin{array}{c}\text { Manel } \\
1.79^{\mathrm{B}}\end{array}$ & $\begin{array}{c}\text { Kounouz } \\
1.74^{\mathrm{B}}\end{array}$ & & $0.045^{*}$ \\
\hline Triticale & $\begin{array}{c}\mathrm{Tcl} 4 \\
1.47^{\mathrm{A}}\end{array}$ & $\begin{array}{l}\mathrm{Tcl} 3 \\
1.42^{\mathrm{B}}\end{array}$ & & & $0.016^{*}$ \\
\hline Oat & $\begin{array}{c}\text { Fretissa } \\
5.97^{\mathrm{A}}\end{array}$ & $\begin{array}{c}\text { Bysantina } \\
5.93^{\mathrm{A}}\end{array}$ & & & 0.910 \\
\hline Maize & $\begin{array}{c}\text { Grombalia } \\
4.71\end{array}$ & & & & - \\
\hline $\begin{array}{l}\text { Pearl } \\
\text { millet }\end{array}$ & $\begin{array}{c}\text { Medenine } \\
5.06\end{array}$ & & & & - \\
\hline
\end{tabular}

Means with different letters (A, B, C) were significantly different (Duncan grouping test at the $5 \%$ probability level). Pr: probability; $P \leq 0.05$ : significant; $P>0.05$ not significant.

\section{Results}

3.1. Total Lipid Percentage. Table 2 shows that the lipid content in durum wheat varieties was $1.81 \%$. Statistical analysis showed no significant differences in lipid content between varieties (Table 2).

In bread wheat varieties, the lipid content was on average $1.69 \%$. Compared to durum wheat, lipid content was significantly lower in this species. The highest value was $1.85 \%$ recorded in Aicha variety, while the lowest was $1.52 \%$ reported in Salambo. High significant differences $(P<0.001)$ in lipid content were found when these varieties were compared (Table 2).

In barley, the lipid content was $1.84 \%$. Analysis of variance indicated significant genotypic variation $(P<0.05)$ with two class levels. Rihane variety formed the major lipid class (A), while Manel and Kounouz represented the minor class (B). The average lipid content in barley varieties was significantly higher than in those of bread and durum wheat.

Lipid content reported in triticale was $1.44 \%$. Significant difference was found between the two varieties Tcl4 and Tcl3. Apart from that, the lipid percentage in triticale was significantly lower than that of wheat and barley.

Maize and millet varieties had significantly higher lipid content $(4.71 \%$ and $5.06 \%)$ than those of wheat, barley, and triticale. With a high amount of lipids (5.95\%), oat took the first place among all studied cereal species.

According to Table 3, cereal species were classified in six groups with a high significant difference between species. The highest percentage of lipids among the 7 species was found in oats $\left(5.95^{\mathrm{A}} \%\right)$, while the lowest content was found in triticale $\left(1.44{ }^{\mathrm{E}} \%\right)$.

\subsection{Fatty Acid Analysis}

3.2.1. Durum Wheat. For durum wheat, Khiar variety had the highest number of fatty acids (11) while Karim had the lowest number (7) (Tables 4 and 5). With a high percentage of $\mathrm{C} 18: 2$, Karim is also characterized by the absence of $\mathrm{C} 18$ : 
TABLE 3: Variation of total lipid (\%) of the 7 cereal species.

\begin{tabular}{lcccccc}
\hline Species & Oat & Pearl millet & Maize & Barley & D. wheat & B. wheat \\
\hline Total lipid & $5.95^{\mathrm{A}}$ & $5.06^{\mathrm{B}}$ & $4.71^{\mathrm{C}}$ & $1.84^{\mathrm{D}}$ & $1.81^{\mathrm{D}}$ & $1.69^{\mathrm{DE}}$ \\
\hline \multirow{2}{*}{ Source } & $\mathrm{DF}$ & $\mathrm{MS}$ & $\mathrm{F}$ & $\mathrm{Pr}$ & \\
& 6 & 21.602 & 527.09 & $0.0001^{* * *}$ & & \\
\hline
\end{tabular}

Means with different letters (A, B, C, D, E) were significantly different (Duncan grouping at the $5 \%$ probability level). MS: mean square.

TABle 4: Fatty acid composition (\%: relative percent) and retention time (RT, min) of durum wheat, bread wheat, and barley varieties.

\begin{tabular}{|c|c|c|c|c|c|c|c|c|c|c|c|c|c|}
\hline \multirow[b]{2}{*}{$\mathrm{N}^{\circ}$} & \multicolumn{6}{|c|}{ Durum wheat } & \multicolumn{3}{|c|}{ Bread wheat } & \multicolumn{3}{|c|}{ Barley } & \multirow[b]{2}{*}{ Fatty acids } \\
\hline & RT & $\begin{array}{c}\mathrm{Raz} \\
\%\end{array}$ & $\begin{array}{c}\text { Kar } \\
\%\end{array}$ & $\begin{array}{c}\text { Khi } \\
\%\end{array}$ & $\begin{array}{c}\text { Maa } \\
\%\end{array}$ & $\begin{array}{c}\text { Sal } \\
\% \\
\end{array}$ & $\begin{array}{c}\text { Byr } \\
\% \\
\end{array}$ & $\begin{array}{c}\text { Uti } \\
\%\end{array}$ & $\begin{array}{c}\text { Aic } \\
\% \\
\end{array}$ & $\begin{array}{c}\text { Man } \\
\%\end{array}$ & $\begin{array}{c}\text { Kou } \\
\%\end{array}$ & $\begin{array}{c}\text { Rih } \\
\%\end{array}$ & \\
\hline 1 & 5.31 & - & 0.15 & 0.06 & - & 0.08 & 0.08 & 0.07 & 0.07 & 0.15 & 0.15 & 0.07 & $\mathrm{C} 14: 0$ \\
\hline 2 & 6.40 & - & - & 0.09 & 0.13 & - & 0.08 & 0.08 & 0.08 & - & - & 0.08 & $\mathrm{C} 15: 0$ \\
\hline 3 & 7.74 & 15.34 & 19.0 & 16.17 & 15.05 & 17.19 & 15.50 & 16.83 & 16.25 & 19.05 & 19.05 & 16.23 & $\mathrm{C} 16: 0$ \\
\hline 4 & 8.14 & 0.20 & - & 0.19 & 0.17 & 0.14 & 0.21 & 0.18 & 0.23 & - & - & 0.23 & $\mathrm{C} 16: 1$ \\
\hline 5 & 10.83 & 1.45 & 1.56 & 1.20 & 1.44 & 1.14 & 1.28 & 1.00 & 0.97 & 1.56 & 1.56 & 1.02 & C18:0 \\
\hline 6 & 11.28 & 22.98 & 15.70 & 20.96 & 21.60 & 16.11 & 18.98 & 19.27 & 17.24 & 15.70 & 15.70 & 17.43 & $\mathrm{C} 18: 1$ cis \\
\hline 7 & 11.35 & 0.89 & - & 0.84 & 0.82 & 0.76 & - & - & - & - & - & - & $\mathrm{C} 18: 1$ trans \\
\hline 8 & 12.16 & 54.43 & 57.45 & 54.9 & 55.69 & 59.10 & 57.10 & 57.26 & 60.13 & 57.45 & 57.45 & 59.94 & $\mathrm{C} 18: 2$ w6 cis \\
\hline 9 & 13.23 & 4.03 & 5.33 & 4.52 & 4.11 & 4.20 & 3.68 & 4.16 & 3.94 & 5.33 & 5.33 & 3.92 & $\mathrm{C} 18: 3 \omega-3$ \\
\hline 10 & 14.34 & 0.09 & - & 0.25 & 0.19 & 0.17 & 0.18 & 0.14 & 0.14 & - & - & 0.14 & $\mathrm{C} 20: 0$ \\
\hline 11 & 14.76 & 0.54 & 0.72 & 0.77 & 0.75 & 1.06 & 0.87 & 0.80 & 0.77 & 0.72 & 0.72 & 0.77 & $\mathrm{C} 20: 1$ \\
\hline 12 & 15.70 & - & - & - & - & - & - & 0.15 & 0.12 & - & - & 0.13 & $\mathrm{C} 20: 2$ \\
\hline
\end{tabular}

Cultivars: Raz: Razzak; Kar: Karim; Khi: Khiar; Sal: Salambo; Byr: Byrsa; Uti: Utique; Aic: Aicha; Man: Manel; Kou: Kounouz; Rih: Rihane.

TABLE 5: Number and amount of the different fatty acids fractions of durum wheat, bread wheat, and barley varieties.

\begin{tabular}{|c|c|c|c|c|c|c|c|c|c|c|c|}
\hline & \multicolumn{4}{|c|}{ Durum wheat } & \multicolumn{4}{|c|}{ Bread wheat } & \multicolumn{3}{|c|}{ Barley } \\
\hline & $\mathrm{Raz}$ & Kar & Khi & Maa & Sal & Byr & Uti & Aic & Man & Kou & Rih \\
\hline TFAn & 9 & 7 & 11 & 10 & 10 & 10 & 11 & 11 & 7 & 7 & 11 \\
\hline SFAn & 3 & 3 & 5 & 4 & 4 & 5 & 5 & 5 & 3 & 3 & 5 \\
\hline$\%$ SFA & 16.8 & 24 & 17.7 & 16.8 & 18.5 & 17.1 & 18.1 & 17.5 & 20.7 & 20.7 & 17.5 \\
\hline MUSFAn & 4 & 2 & 4 & 4 & 4 & 3 & 3 & 3 & 2 & 2 & 3 \\
\hline$\%$ MUSFA & 24.1 & 16.4 & 22.7 & 23.3 & 18.0 & 20.0 & 20.2 & 18.2 & 16.4 & 16.4 & 18.4 \\
\hline PUSFAn & 2 & 2 & 2 & 2 & 2 & 2 & 3 & 3 & 2 & 2 & 3 \\
\hline $\begin{array}{l}\% \text { PUSFA } \\
\text { PU/MU }\end{array}$ & 58.4 & 62.7 & 59.4 & 59.8 & 63.3 & 60.7 & 61.5 & 64.1 & 62.7 & 62.7 & 63.9 \\
\hline (R1) & 2.37 & 3.82 & 2.61 & 2.56 & 3.50 & 3.02 & 3.04 & 3.51 & 3.82 & 3.82 & 3.47 \\
\hline U/S (R2) & 4.92 & 3.30 & 4.63 & 4.94 & 4.38 & 4.72 & 4.51 & 4.70 & 3.81 & 3.81 & 4.69 \\
\hline
\end{tabular}

TFAn: total fatty acids number; SFAn: saturated fatty acids number; \% SFA: \% of saturated fatty acids; MUSFAn: monounsaturated fatty acids number; $\%$ MUSFA: \% of monounsaturated fatty acids; PUSFAn: polyunsaturated fatty acids number; \% PUSFA: \% of polyunsaturated fatty acids; PU/MU: polyunsaturated/monounsaturated (R1); U/S: unsaturated/saturated (R2). Varieties: Raz: Razzak; Kar: Karim; Khi: Khiar; Sal: Salambo; Byr: Byrsa; Uti: Utique; Aic: Aicha; Man: Manel; Kou: Kounouz; Rih: Rihane.

1 trans. Polyunsaturated fatty acids recorded in durum wheat oil included the essential fatty acids: C18:2 (linoleic acid) and C18:3 (oleic acid). The main fatty acid observed was $\mathrm{C} 18: 2$ with a total percentage ranging from $54.43 \%$ in Razzak to $57.45 \%$ in Karim. The major monounsaturated fatty acid was $\mathrm{C} 18: 1$, whereas the main saturated fatty acid was C16:0 (palmitic acid) (Table 4). Results demonstrate that $\mathrm{C} 18: 1$ cis and $\mathrm{C} 18: 2$ were the most presented in durum wheat varieties. C18:1 is the only fatty acid found in both cis and trans configurations in all varieties except Karim. Furthermore, one atypical odd fatty acid, the pentadecanoic C15:0, was found in two cultivars Maali and Khiar.

Table 5 shows that, in spite of the existence of only two acids, the polyunsaturated fatty acid content was predominant in all cultivars, except Karim. The percentage was ranged from $58.46 \%$ in Razzak to $62.78 \%$ in Karim. The content of monounsaturated ranged from $16.42 \%$ in Karim to $24.61 \%$ in Razzak. The highest value of saturated fatty acids was recorded in Karim (24\%), whereas the lowest was reported in Maali variety $(16.81 \%)$.

3.2.2. Bread Wheat. As shown in Tables 4 and 5 and compared to durum wheat, the results showed a new fatty acid C20:2, eicosadienoic, that appeared only in two cultivars (Utique and Aicha) which had the highest number of fatty acids (11). Contrary to durum wheat, in bread wheat C18:1 trans is absent in all varieties except Salambo. The 
main fatty acid observed in this specie was $\mathrm{C} 18: 2$ with a percentage higher than those of durum wheat $(54.43 \%$ to $57.45 \%$ ) and ranged from $57.10 \%$ in Byrsa to $60.13 \%$ in Aicha.

Polyunsaturated fatty acids found in bread wheat were $\mathrm{C} 18: 2, \mathrm{C} 18: 3$, and $\mathrm{C} 20: 2$. The major monounsaturated fatty acid in all bread wheat varieties was the oleic acid (C18: 1) $(16.11 \%$ to $19.27 \%)$, whereas the main saturated fatty acid was the palmitic acid (C16:0) which ranged from $15.50 \%$ to $17.19 \%$. In addition, one odd fatty acid, pentadecanoic (C15 : 0 ), was present in all varieties except Salambo variety. The percent of saturated fatty acids in bread wheat varieties was similar to that of monounsaturated fatty acids, whereas polyunsaturated acids rate was much higher (Table 5). From $60.78 \%$ to $64.19 \%$ in bread wheat, these values were higher than the values previously reported in durum wheat $(58.46 \%$ to $62.78 \%)$.

The polyunsaturated/monounsaturated (R1) in bread wheat that ranged from 3.02 to $3.51 \%$ was higher than in those of durum wheat except for one variety. The unsaturated/saturated fatty acids ratio (R2) was higher in durum wheat than in bread wheat except Karim variety. Results of Table 5 indicate that R2 was superior to $4 \%$ for all bread wheat cultivars. With a high value, the unsaturated/saturated fatty acid ratio of Byrsa was similar to Aicha with higher values than those in Utique and Salambo varieties.

3.2.3. Barley. Tables 4 and 5 show that the fatty acids number varied between 7 in both cultivars Manel and Kounouz and 11 in Rihane. As in bread wheat, the results demonstrated that the fatty acid C20:2 appeared also in barley (Rihane) (Table 4). Compared with the results of durum and bread wheat, in barley cultivars, C18:1 trans did not exist in none cultivar. Table 4 shows also that the major fatty acid observed in barley varieties was C18:2 (polyunsaturated fatty acid). Compared to durum wheat $(54.43 \%-$ $57.45 \%)$ and bread wheat $(57.10 \%-60.13 \%)$, the percentage of this acid ranged from $57.45 \%$ to $59.94 \%$.

Barley cultivars had the same polyunsaturated fatty acids in comparison with bread wheat $(\mathrm{C} 18: 2, \mathrm{C} 18: 3$ and $\mathrm{C} 20: 2)$. $\mathrm{C} 18: 1$ cis remained the major monounsaturated fatty acid in barley and C20:1 was found in all varieties.

Table 5 shows that the highest fraction of fatty acids in barley was represented by the polyunsaturated acids, followed by saturated and monounsaturated fatty acids. Compared to durum wheat (58.46\% to $62.78 \%)$ and bread wheat $(60.78 \%$ to $64.19 \%)$, the percentage of the major fraction in barley varied between $62.78 \%$ and $63.99 \%$.

Compared with $\mathrm{R} 1$, the $\mathrm{R} 2$ ratio (unsaturated/saturated fatty acids) was similar for Manel and Kounouz and significantly much higher for Rihane compared to other varieties.

3.2.4. Triticale. Fatty acid composition and the retention time illustrated in Table 6 did not differ between the triticale varieties. The total number of fatty acids in triticale was lower (7) compared to other species. As in barley, C18:1 trans did not exist in this species. The major fatty acid observed in triticale was a polyunsaturated fatty acid: C18:2 with a percentage of $57.45 \%$. C18:1 cis was the main monounsaturated fatty acid (15.70\%), whereas C16:0 was the mainly saturated fatty acid (19.05\%).

The percentage of polyunsaturated, saturated, and monounsaturated fatty acids in triticale was $62.78 \%, 20.76 \%$, and $16.42 \%$, respectively (Table 7 ). These compositions and classifications were similar to those of barley cultivars. Polyunsaturated/monounsaturated fatty acids ratio (R1) was relatively similar to the unsaturated/saturated fatty acids ratio (R2) for the two varieties.

3.2.5. Oat. According to Table 6, the fatty acid composition did not differ between the two studied oat varieties. Compared to wheat (durum, bread) and barley, the number of fatty acids observed in oat was significantly lower (7). We noted also that the C18:1 trans was not found in oat varieties. Contrary to wheat, barley, and triticale, the main fatty acid recorded in oat was a monounsaturated fatty acid: C18: 1 cis with a percentage of $49.07 \%$. C18:2, which considered as the major fatty acid in the other species, in oat cultivars, occupied the second position followed by C16:0.

The percentage of fatty acids classes was similar in both oat varieties. Contrary to the other species, monounsaturated fatty acids constituted the highest fraction (50.47\%); however, polyunsaturated fatty acids represented the smallest compound (23.92\%) (Table 7).

In contrast to the other studied species with a polyunsaturated/monounsaturated fatty acids ratio that ranged from $2.37 \%$ to 3.82 , in oat, this ratio was very weak $(0.47 \%)$.

3.2.6. Maize and Pearl Millet. Table 6 shows that maize and millet (C4 plants) did not show any difference. Fatty acids number was similar in both species and it was lower than that observed in wheat and barley. On the other hand, maize and pearl millet were also richer in linoleic acid C18:2 $(47.50 \%)$ and did not show the presence of trans fatty acid configuration.

Table 7 shows that the percentage of the different fatty acid fractions was similar for both species, maize and pearl millet. As for durum and bread wheat, the major fraction of fatty acids in maize and pearl millet was represented by the polyunsaturated fatty acids (49.65\%) followed by monounsaturated (27.57\%) and saturated fatty acids (22.75\%).

The ratio $\mathrm{R} 1$ of maize and pearl millet varieties was lower than that observed for wheat, barley, and triticale whereas R2 was similar to these species.

Results concluded that the unsaturated fatty acids fractions of the studied cereal species showed a greater source of variation. On average (Figure 1), the tested species showed a variation of the polyunsaturated fatty acids percentage from $23.92 \%$ in oat to $63.18 \%$ in barley varieties. All studied cereal species had a percentage of polyunsaturated fatty acids approximately higher than the half of the total fatty acids and much higher than those of oat varieties. Polyunsaturated fractions in $\mathrm{C} 4$ plant species, maize and pearl millet, were similar $(49.65 \%)$, while for durum wheat, bread wheat, barley, and triticale this fraction was 
TABLE 6: Fatty acid composition (\%: relative percent) and retention time (RT, min) of triticale, oat, maize, and pearl millet varieties.

\begin{tabular}{|c|c|c|c|c|c|c|c|c|}
\hline \multirow[b]{2}{*}{ No. } & \multirow[b]{2}{*}{$\mathrm{RT}$} & \multicolumn{2}{|c|}{ Triticale } & \multicolumn{2}{|c|}{ Oat } & \multirow{2}{*}{$\begin{array}{c}\text { Maize } \\
\text { Grombalia } \\
\%\end{array}$} & \multirow{2}{*}{$\begin{array}{c}\text { P. millet } \\
\text { Medenine } \\
\%\end{array}$} & \multirow[b]{2}{*}{ Fatty acids } \\
\hline & & $\begin{array}{c}\mathrm{Tcl} 3 \\
\%\end{array}$ & $\begin{array}{c}\mathrm{Tcl} 4 \\
\%\end{array}$ & $\begin{array}{c}\text { Bysantina } \\
\%\end{array}$ & $\begin{array}{c}\text { Fretissa } \\
\%\end{array}$ & & & \\
\hline 1 & 5.31 & 0.15 & 0.15 & 0.25 & 0.25 & - & - & $\mathrm{C} 14: 0$ \\
\hline 2 & 5.98 & - & - & 0.16 & 0.16 & - & - & $\mathrm{C} 14: 1$ \\
\hline 3 & 7.74 & 19.05 & 19.05 & 22.73 & 22.73 & 16.79 & 16.79 & $\mathrm{C} 16: 0$ \\
\hline 4 & 8.14 & - & - & - & - & 0.29 & 0.29 & $\mathrm{C} 16: 1$ \\
\hline 5 & 10.83 & 1.56 & 1.56 & 2.60 & 2.60 & 5.02 & 5.02 & C18:0 \\
\hline 6 & 11.28 & 15.70 & 15.70 & 49.07 & 49.07 & 27.07 & 27.07 & $\mathrm{C} 18: 1 \mathrm{cis}$ \\
\hline 7 & 12.16 & 57.45 & 57.45 & 23.47 & 23.47 & 47.50 & 47.50 & $\mathrm{C} 18: 2 \omega 6$ cis \\
\hline 8 & 13.23 & 5.33 & 5.33 & 0.45 & 0.45 & 2.15 & 2.15 & $\mathrm{C} 18: 3 \omega 3$ \\
\hline 9 & 14.34 & - & - & - & - & 0.94 & 0.94 & C20:0 \\
\hline 10 & 14.76 & 0.72 & 0.72 & 1.24 & 1.24 & 0.21 & 0.21 & $\mathrm{C} 20: 1$ \\
\hline
\end{tabular}

TAвLE 7: Number and amount of the different fatty acids fractions of triticale, oat, maize, and pearl millet varieties.

\begin{tabular}{|c|c|c|c|c|c|c|}
\hline & \multicolumn{2}{|c|}{ Triticale } & \multicolumn{2}{|c|}{ Oat } & \multirow{2}{*}{$\begin{array}{c}\text { Maize } \\
\text { Grombalia }\end{array}$} & \multirow{2}{*}{$\begin{array}{l}\text { P. millet } \\
\text { Médenine }\end{array}$} \\
\hline & $\mathrm{Tcl} 3$ & $\mathrm{Tcl} 4$ & Bysantina & Fretissa & & \\
\hline TFAn & 7 & 7 & 8 & 8 & 8 & 8 \\
\hline SFAn & 3 & 3 & 3 & 3 & 3 & 3 \\
\hline$\%$ SFA & 20.76 & 20.76 & 25.58 & 25.58 & 22.75 & 22.75 \\
\hline MUSFAn & 2 & 2 & 3 & 3 & 3 & 3 \\
\hline$\%$ MUSFA & 16.42 & 16.42 & 50.47 & 50.47 & 27.57 & 27.57 \\
\hline PUSFAn & 2 & 2 & 2 & 2 & 2 & 2 \\
\hline$\%$ PUSFA & 62.78 & 62.78 & 23.92 & 23.92 & 49.65 & 49.65 \\
\hline PU/MU (R1) & 3.82 & 3.82 & 0.47 & 0.47 & 1.80 & 1.80 \\
\hline $\mathrm{U} / \mathrm{S}(\mathrm{R} 2)$ & 3.81 & 3.81 & 2.90 & 2.90 & 3.39 & 3.39 \\
\hline
\end{tabular}

TFAn: total fatty acids number; SFAn: saturated fatty acids number; $\%$ SFA: $\%$ of saturated fatty acids; MUSFAn: monounsaturated fatty acid number; $\%$ MUSFA: \% of monounsaturated fatty acids; PUSFAn: polyunsaturated fatty acid number; \% PUSFA: \% of polyunsaturated fatty acids; PU/MU: polyunsaturated/monounsaturated (R1); U/S: unsaturated/saturated (R2).

considerably higher and was, respectively, 60.11\%, 62.46\%, $63.18 \%$, and $62.78 \%$. The monounsaturated fatty acid fraction was lower for all species except for oat which reached $50.47 \%$. The average of total unsaturated fatty acid in all studied species (ranging from 77.22 to $81.89 \%$ ) was significantly higher in durum and bread wheat, and barley than in triticale, oat, maize, and pearl millet, respectively. In regard to the polyunsaturated fraction, the present results indicate that barley $(63.18 \%)$ and triticale $(62.78 \%)$ were the most polyunsaturated species, whereas for the total unsaturated fatty acids fraction, durum wheat $(81.89 \%)$ followed by bread wheat $(81.61 \%)$ were the most unsaturated species.

\section{Discussion}

In addition to proteins and carbohydrates, lipids are among the three main classes of food products [14]. This investigation presented the content and composition of lipids of 17 cereal varieties belonging to 7 species. Our results showed that total lipids ranged from $1.42 \%$ to $5.97 \%$. This result was in agreement with that of [15] which showed that most cereal grains were low in lipid content. The present study showed that cereal species were classified in six groups with high significant differences. The highest percentage of total lipids was $5.95 \%$ recorded in oat, while the lowest content was found in triticale (1.44\%). In average, the C4 plants, maize and pearl millet, had significantly higher lipid content
(4.71\% and 5.06\%) than those of C3 barley (1.84\%), durum wheat $(1.81 \%)$, and bread wheat (1.69\%) except oat. These values were similar to those previously reported by [9] which ranged between $2.18 \%$ (wheat) and $6.38 \%$ (oat).

Among all tested cereals, oat with the highest lipid percentage, as shown by Cozzolino et al. [13], was unique because of their high oil content. Studies $[9,16,17]$ showed also in different oat cultivars that the lipid content ranged from 5 to $8 \%$; it makes the oat a potentially oilseed crop.

The pearl millet species with a lipid percentage of 5.06\% (the second position) had a great potential in industrial foods (pasta, snack, and cakes). It was considered also as an important source of nutraceuticals of cholesterol-lowering waxes [18]. Study [19] observed a significant raise of glycemic index after removal of lipid from pearl millet. We therefore advocate the use of whole pearl millet grains in the industrial foods to maintain the hypoglycemic properties.

In this work, we were interested also in studying maize oil which is one of the most cereal species used in the extraction of edible oil. In recent years, we were interested in the breeding programs of maize to the nutritional properties [20] and the composition of oil and fatty acids of this species [21]. Our results showed that the maize species had a lipid content equal to $4.71 \%$. This result was in agreement with that recorded by [22].

The lipid content in durum wheat reached $1.88 \%$; this fraction affected partially the cooking quality of couscous 


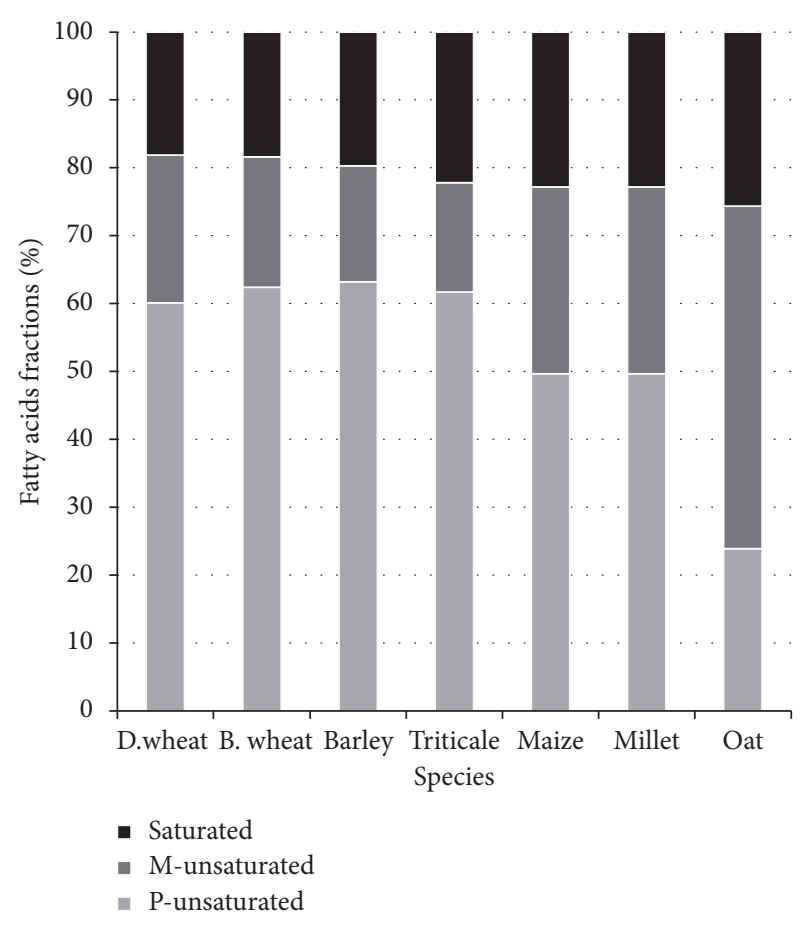

FIGURE 1: The saturated and unsaturated fatty acids fractions (\%) of the studied cereal species; M: mono, P: poly.

[11]. Indeed, the polar lipid fractions in durum wheat grain affect couscous texture in terms of firmness, couscous swelling, and caking index [11].

For bread wheat lipids, significant differences were found among varieties and the content reached $1.85 \%$. This variation depended on genetic characteristics and abiotic factors [23]. Despite the minor proportion in flour wheat, lipids displayed essential functional properties in bread making [8]. The composition and structure of lipids in bread wheat influence the quality of bread [10]. Bread wheat lipids play also an essential role in other food systems such as pasta, cakes, and cookies. The interaction between total lipids and other substances determined largely the quality of those foods [24]. Consequently, Maali cultivar (Durum wheat) and Aicha cultivar (Bread wheat) will be recommended in the industrial alimentary such as semolina (couscous), bread making, pasta, cakes, and cookies.

This work presented also the composition of cereals in fatty acids. The major fatty acid recorded in all studied cereal species, except oat, was $\mathrm{C} 18: 2$, whereas, for oat, the main fatty acid was oleic acid C18:1 cis. These results are in agreement with those obtained by [25] in wheat grain oil. Oat differs from other cereals, with grain lipids composed essentially of unsaturated oleic $(18: 1)$ [26-28]. Despite the low oil contents, our studied species represented an excellent source of essential fatty acids with an elevated degree of unsaturation. For this reason, cereal grains deserve a focused interest due to their fatty acid composition and their vitamin $E$ composition [29]. This study showed that oleic acid C18:1 cis, compared to others fatty acids, represented the highest fraction in oat $49.07 \%$ (first position) and the second place in the other species with a highest value observed in millet
(27.07\%). According to [5], the oleic acid C18:1 has a major role in the starch hydrolysis and in the hypoglycemic properties of millet. Consequently, oat and millet oils may be used as a new oil source due to the presence of numerous essential and unsaturated fatty acids and can play a significant role in the hyper-glycemic diet [30].

Our results showed also that $\mathrm{C} 18: 2$ was the main fatty acid in the cereal grains. According to [31], all cereal grain lipids have a high level of unsaturated fatty acids such as linoleic $(18: 2)$, exception oat, which has a major fatty acid C18:1. Deficiency of C18:2 caused an increase of skin permeability, a decrease of growth, and malfunctions of organs. Consequently, the porridge prepared from cereals grains is important for infants and children [32]. This study showed that the oils grains of durum and bread wheat, triticale, barley, millet, and maize were rich in $\omega 6$ fatty acid (47.50 to $60.13 \%$ ), whereas oat grains were poor in this essential fatty acid (23.47\%). The linolenic acid 18:3, recorded in low fraction in all species, fluctuated between $0.45 \%$ in oat and $5.33 \%$ in triticale, barley, and one durum wheat cultivar (Karim). The presence of essential fatty acids increases the value of cereal lipids because they play a significant role as precursors of some biomolecules in the human body [23]. Because these essential fatty acids cannot be synthesized in humans, the only solution will be to look for food $[33,34]$ as cereal oil to supplement these fatty acids.

All studied cereal species, except oat, had a high value of $\omega 6$ and a low percentage of $\omega 3$; these results are in accordance with those of [32]. Therefore, the production of $\omega 3$ fatty acid from other species is very important for both health food and pharmaceutical industries. Indeed, both $\omega 3$ and $\omega 6$ are precursors of hormone like eicosanoids [35]. With a ratio of $\omega 6 / \omega 3$ from 3 to 5 , these acids were considered as essential fatty acids in infant nutrition [36]. Therefore, the studied cereal species can be used as edible oil rich in linoleic acid (C18:2), and the relatively high level of C18:3 made these oils nutritionally precious due to its positive effects on the cancer prevention and the cardiovascular diseases [37]. Hence, determining the fatty acids of cereal lipid facilitated the evaluation of its potential nutritive and structural values. The polyunsaturated fatty acids have a significant role in the determination of the structure and function of some membrane proteins [38]. A diet with a considerable monounsaturated fatty acids content reduces blood cholesterol level [39] and increases the HDL fluidity [40]. Consequently, the studied cereal species which had a high polyunsaturated fatty acids percentage (barley: $63.18 \%$ and triticale: $62.78 \%$ ) and a high total unsaturated fatty acids fraction (durum wheat: $81.89 \%$, bread wheat: $81.61 \%$ ) seem to be very important in our alimentary diet.

Among all species, oat had the smallest unsaturated fraction $(74.39 \%)$ and the lowest polyunsaturated acids content $(23.92 \%)$, whereas monounsaturated acids represented the highest fraction (50.47\%). Therefore, oat lipids were regarded as nutritionally important because they show very high monounsaturated fatty acids [41].

One odd fatty acid (pentadecanoic; C15:0) was present in some varieties of durum wheat, bread wheat, and barley. This fatty acid is essential for humans. In plasma, despite the 
low concentration of odd-chain fatty acids as C15:0, their chemical properties and biological activities are currently widely studied [28].

Contrary to [42] which found in winter wheat cultivars four trans fatty acids (C18:2, C18:1, C18:3 $\omega 3$ and C18: $3 \omega 6)$, ours results showed only one fatty acid (C18:1) in both cis and trans configurations found in only two cereal species (3 durum wheat varieties and one bread wheat variety). Fortunately, the form of trans-isomer in these species was lower and constituted about $0.76 \%$ to $0.89 \%$. According to [43], infant foods should not contain trans fatty acids. For adults, consumption of trans fatty acids leads to an increase of the cholesterol level and a decrease of LDL density in plasma $[44,45]$. Therefore, avoiding processes that has the tendency of changing the configuration of unsaturated fatty acids to the trans form was important in keeping the beneficially low hypoglycemic property of cereal species [5].

\section{Conclusion}

This study aimed to evaluate the lipid composition of cereal seeds. No other studies, to our knowledge, have studied the lipid content and fatty acid of all cereal species cultivated in Tunisia. Consequently, our results provide a main database of lipids and fatty acids of the most cereal species commonly cultivated worldwide. All studied oils contained a high content of two essential fatty acids, C18:2 ( $\omega 6)$ and C18:3 $(\omega 3)$, which are the starting points for the synthesis of many unsaturated fatty acids. Cereal lipid could provide the daily requirement in essential fatty acids for individuals in Tunisia and in the Mediterranean zone where large amounts of cereals (bread and durum wheat) are eaten as paste, bread, or couscous. In addition, due to the presence of many unsaturated and essential fatty acids necessary for human health, maize and millet could be essential in the future because there is today at a worldwide level a rising demand of foods without gluten for coeliacs people. Thus, it is essential to produce gluten-free pasta and bread from maize and millet flours. Finely, barley and triticale were the most polyunsaturated species and did not show any presence of fatty acids trans form. Barley and triticale could be used as fundamental species in diet alimentary.

As cereals are usually processed to consumer products, many changes can render lipids more susceptible towards deteriorative reactions. We should pay more attention to the processing techniques that can be used to preserve the quality of cereal lipids and enhance their benefits.

\section{Data Availability}

All data underlying the findings are fully available without restriction in this manuscript version; no repository information and no supporting information will be added.

\section{Conflicts of Interest}

The authors declare that they have no conflicts of interest.

\section{Acknowledgments}

This work was supported by the Laboratory of Neurophysiology, Cellular Physiopathology and Biomolecules Valorisation LR18ES03, University of Tunis El Manar, Faculty of Sciences of Tunis, 2092 Tunis, Tunisia.

\section{References}

[1] O. K. Chung, J. B. Ohm, M. S. Ram, S. H. Park, and C. A. Howitt, Chapter 10 - Wheat Lipids, AACC International Press, Cambridge, MA, USA, 2009.

[2] S. Mehmood, I. Orhan, Z. Ahsan, S. Aslan, and M. Gulfraz, "Fatty acid composition of seed oil of different sorghum bicolor varieties," Food Chemistry, vol. 109, no. 4, pp. 855-859, 2008.

[3] V. Patil and H. R. Gislerod, "The importance of omega-3 fatty acids in diet," Current Science-Bangalore, vol. 90, no. 7, p. 908, 2006.

[4] H. Iso, S. Sato, U. Umemura et al., "Linoleic acid, other fatty acids, and the risk of stroke," Stroke, vol. 33, no. 8, pp. 2086-2093, 2002.

[5] G. A. Annor, M. Marcone, M. Corredig, E. Bertoft, and K. Seetharaman, "Effects of the amount and type of fatty acids present in millets on their in vitro starch digestibility and expected glycemic index (EGI)," Journal of Cereal Science, vol. 64, pp. 76-81, 2015.

[6] J. Slavin, "Whole grains and digestive health," Cereal Chemistry, vol. 87, no. 4, pp. 292-296, 2010.

[7] S. Kalayc1 and Ö. Yılmaz, "Effect of cereal grains on the total lipid, cholesterol content and fatty acid composition of liver and muscle tissues in native geese," vol. 20, no. 1, pp. 27-34, 2014, https://app.trdizin.gov.tr/dergi/TVRrMU5RPT0/ kafkas-universitesi-veteriner-fakultesi-dergisi.

[8] B. Pareyt, S. M. Finnie, J. A. Putseys, and J. A. Delcour, "Lipids in bread making: sources, interactions, and impact on bread quality," Journal of Cereal Science, vol. 54, no. 3, pp. 266-279, 2011.

[9] K. Liu, "Comparison of lipid content and fatty acid composition and their distribution within seeds of 5 small grain species," Journal of Food Science, vol. 76, no. 2, pp. C334-C342, 2011.

[10] S. M. Finnie, R. Jeannotte, and J. M. Faubion, "Quantitative characterization of polar lipids from wheat whole meal, flour, and starch," Cereal Chemistry Journal, vol. 86, no. 6, pp. 637-645, 2009.

[11] G. Ounane, B. Cuq, J. Abecassis, A. Yesli, and S. M. Ounane, "Effects of physicochemical characteristics and lipid distribution in Algerian durum wheat semolinas on the technological quality of couscous," Cereal Chemistry, vol. 83, no. 4, pp. 377-384, 2006.

[12] G. Zhang and B. R. Hamaker, "Sorghum (sorghum bicolor L. Moench) flour pasting properties influenced by free fatty acids and protein," Cereal Chemistry Journal, vol. 82, no. 5, pp. 534-540, 2005.

[13] D. Cozzolino, S. Roumeliotis, and J. Eglinton, "Relationships between starch pasting properties, free fatty acids and amylose content in barley," Food Research International, vol. 51, no. 2, pp. 444-449, 2013.

[14] A. Slama, R. Hammami, A. Cherif, H. C. M'hamed, and S. Boukhchina, "Valorisation of oils extracted from four Tunisian citrus species seeds," Rivista Italiana Delle Sostanze Grasse, vol. 97, no. 3, pp. 47-54, 2020. 
[15] J. B. Holland, K. J. Frey, and E. G. Hammond, "Correlated responses of fatty acid composition, grain quality, and agronomic traits to nine cycles of recurrent selection for increased oil content in oat," Euphytica, vol. 122, no. 1, pp. 69-79, 2001.

[16] S. Leonova, T. Shelenga, M. Hamberg, A. V. Konarev, I. Loskutov, and A. S. Carlsson, "Analysis of oil composition in cultivars and wild species of oat (avena sp.)," Journal of Agricultural and Food Chemistry, vol. 56, no. 17, pp. 79837991, 2008.

[17] G. A. Batalova, V. N. Krasilnikov, V. S. Popov, and E. E. Safonova, "Characteristics of the fatty acid composition of naked oats of Russian selection," IOP Conference Series: Eartvh and Environmental Science, vol. 337, no. 1, Article ID 012039, 2019.

[18] J. R. N. Taylor, T. J. Schober, and S. R. Bean, "Novel food and non-food uses for sorghum and millets," Journal of Cereal Science, vol. 44, no. 3, pp. 252-271, 2006.

[19] G. A. Annor, M. Marcone, E. Bertoft, and K. Seetharaman, "In vitro starch digestibility and expected glycemic index of kodo millet (paspalum scrobiculatum) as affected by starch-protein-lipid interactions," Cereal Chemistry Journal, vol. 90, no. 3, pp. 211-217, 2013.

[20] J. I. Ortiz-Monasterio, N. Palacios-Rojas, E. Meng et al., "Enhancing the mineral and vitamin content of wheat and maize through plant breeding," Journal of Cereal Science, vol. 46, no. 3, pp. 293-307, 2007.

[21] L. Velasco and J. M. Fernández-martínez, "Breeding oilseed crops for improved oil quality," Journal of Crop Production, vol. 5, no. 1-2, pp. 309-344, 2002.

[22] M. G. Vázquez-Carrillo, D. Santiago-Ramos, M. GaytánMartínez, E. Morales-Sánchez, and M. D. J. Guerrero-Herrera, "High oil content maize: physical, thermal and rheological properties of grain, masa, and tortillas," LWT-Food Science and Technology, vol. 60, no. 1, pp. 156-161, 2015.

[23] V. Narducci, E. Finotti, V. Galli, and M. Carcea, "Lipids and fatty acids in Italian durum wheat (Triticum durum desf.) cultivars," Foods, vol. 8, no. 6, 2019.

[24] P. R. Shewry, O. Sayanova, A. S. Tatham et al., "Structure, assembly and targeting of wheat storage protein," Plant Physiology, vol. 145, pp. 620-645, 1995.

[25] W. Tsuzuki, Y. Suzuki, S. Yamada et al., "Effect of oxygen absorber on accumulation of free fatty acids in Brown rice and whole grain wheat during storage," LWT - Food Science and Technology, vol. 58, no. 1, pp. 222-229, 2014.

[26] A. Banas, H. Debski, W. Banas et al., "Lipids in grain tissues of oat (avena sativa): differences in content, time of deposition, and fatty acid composition," Journal of Experimental Botany, vol. 58, no. 10, pp. 2463-2470, 2007.

[27] W. K. Heneen, G. Karlsson, K. Brismar et al., "Fusion of oil bodies in endosperm of oat grains," Planta, vol. 228, no. 4 , pp. 589-599, 2008.

[28] P. Koehler and H. Wieser, Chemistry of Cereal Grains, Springer, Berlin, Germany, 2013.

[29] H. F. Seefeldt, F. H. Larsen, N. Viereck, M. A. Petersen, and S. B. Engelsen, "Lipid composition and deposition during grain filling in intact barley (hordeum vulgare) mutant grains as studied by 1 H HR MAS NMR," Journal of Cereal Science, vol. 54, no. 3, pp. 442-449, 2011.

[30] A. Slama, A. Cherif, F. Sakouhi, S. Boukhchina, and L. Radhouane, "Fatty acids, phytochemical composition and antioxidant potential of pearl millet oil," Journal of Consumer Protection and Food Safety, vol. 15, no. 2, pp. 145-151, 2020.
[31] K. Rosentrater and A. Evers, Kent's Technology of Cereals, Elsevier, Amsterdam, Netherlands, 2018.

[32] M. Asiedu, R. Nilsen, Ø. Lie, and E. Lied, "Effect of processing (sprouting and/or fermentation) on sorghum and maize. I: proximate composition, minerals and fatty acids," Food Chemistry, vol. 46, no. 4, pp. 351-353, 1993.

[33] E. G. Bligh, S. J. Shaw, and A. D. Woyewoda, "Effects of drying and smoking on lipids of fish," 1988, https://agris.fao.org/ agris-search/search.do.

[34] M. Steiner-Asiedu, K. Julshamn, and $\varnothing$. Lie, "Effect of local processing methods (cooking, frying and smoking) on three fish species from Ghana: Part I. Proximate composition, fatty acids, minerals, trace elements and vitamins," Food Chemistry, vol. 40, no. 3, pp. 309-321, 1991.

[35] F. Shahidi and U. N. Wanasundara, "Omega-3 fatty acid concentrates: nutritional aspects and production technologies," Trends in Food Science \& Technology, vol. 9, no. 6, pp. 230-240, 1998.

[36] P. Benatti, G. Peluso, R. Nicolai, and M. Calvani, "Polyunsaturated fatty acids: biochemical, nutritional and epigenetic properties," Journal of the American College of Nutrition, vol. 23, no. 4, pp. 281-302, 2004.

[37] K. W. J. Wahle, S. D. Heys, and D. Rotondo, "Conjugated linoleic acids: are they beneficial or detrimental to health?" Progress in Lipid Research, vol. 43, no. 6, pp. 553-587, 2004.

[38] P. Yaqoob, "Monounsaturated fatty acids and immune function," European Journal of Clinical Nutrition, vol. 56, no. 3, pp. S9-S13, 2002.

[39] R. L. Hargrove, T. D. Etherton, T. A. Pearson, E. H. Harrison, and P. M. Kris-Etherton, "Low fat and high monounsaturated fat diets decrease human low density lipoprotein oxidative susceptibility in vitro," The Journal of Nutrition, vol. 131, no. 6, pp. 1758-1763, 2001.

[40] B. Villa, L. Calabresi, G. Chiesa, P. Risè, C. Galli, and C. R. Sirtori, "Omega-3 fatty acid ethyl esters increase heart rate variability in patients with coronary disease," Pharmacological Research, vol. 45, no. 6, pp. 475-478, 2002.

[41] D. M. Peterson, "Oat antioxidants," Journal of Cereal Science, vol. 33, no. 2, pp. 115-129, 2001.

[42] K. Stuper-Szablewska, M. Buśko, T. Góral, and J. Perkowski, "The fatty acid profile in different wheat cultivars depending on the level of contamination with microscopic fungi," Food Chemistry, vol. 153, pp. 216-223, 2014.

[43] C. Chow, Fatty Acids in Foods and Their Health Implications, CRC Press, Boca Raton, FL, USA, 2007.

[44] C. Akoh and D. Min, Food Lipids: Chemistry, Nutrition, and Biotechnology, Marcel Dekker, New York, NY, USA, 2002.

[45] L. Vijver Van De, A. F. M. Kardinaal, C. Couet et al., "Association between trans fatty acid intake and cardiovascular risk factors in europe: the transfair study," European Journal of Clinical Nutrition, vol. 54, no. 2, pp. 126-135, 2000. 